\title{
Simplified Maintenance Management System for Berth Structure of Ports
}

\author{
Julfikhsan Ahmad Mukhti ${ }^{\# 1}$, Andojo Wurjanto ${ }^{\# 2}$, Rizky Pitajeng ${ }^{* 3}$, Kartika Ayu Savitry ${ }^{* 4}$ \\ \#Ocean Engineering Program, InstitutTeknologi Bandung \\ Jl. Ganesha No.10, Lb. Siliwangi, Coblong, Kota Bandung, Jawa Barat 40132, Indonesia \\ ${ }^{1}$ julfikhsan.am@gmail.com \\ 2 andojowurjanto@gmail.com \\ *PT DinamaritamaKonsultan Rekayasa, Jalan Batik Jonas No. 29 Bandung 40123, Indonesia \\ ${ }^{3}$ rizky.pitajeng@hotmail.com \\ ${ }^{4}$ kartikaayusavitry21@gmail.com
}

\begin{abstract}
The berth facilities owned by national port operators are often deteriorated and regulated maintenance management system is inexistent to detect early deterioration. Currently, monitoring of facilities is only done by request to assess heavily damaged components on the top side of facilities before a repair. However, having this only method prevents the components to be repaired earlier to save costs and left more critical components such as piles to remain unchecked, in which this may lead to complete structural failure. A simple maintenance management system has been proposed to be used by national port operators which consist of monthly monitoring and yearly inspection while still taking the limitations of national port operators in the branches into account. An example of monitoring activity proposed in the system is presented and effective for capturing the general condition of a berth structures as well as the facility health indicator.
\end{abstract}

Keyword - Port, Facilities, Monitoring, Inspection, Maintenance

\section{INTRODUCTION}

Port is one type of the infrastructures that are consistently exposed to both harsh environment and heavy loading from human activities. Port facilities, especially its berth structures, receive loads from the environment as well as become subjected to marine growth. Ship berthing and mooring forces acting on the bollards placed on berth front also affects the durability of the berth structures. In addition to loads from the ship, the upper side of berth structures is also occasionally loaded by heavy vehicles and machinery such as cargo trucks and cranes.

This environment and the human activities on the port led to the high amount of deterioration of facilities as well as lower lifespan design expectation compared to other types of infrastructure. As mentioned by International Navigation Association [1] and Port Technology Group [2], compared to 120 years of highway or rail structures lifespan, typical port structures have a relatively lower design lifespan of 50 to 80 years due to its harsher environment. Zhang et al. [3] have done a simulation based on the facility data from Tokyo Port using Markov chain model to model the deterioration rate of the port. According to the simulation result, it was found that the deck-on-pile structure components quality on the Tokyo Port degrades quickly in the beginning and slows down as the structure deterioration level becomes higher, typically after 10 years.

This port deterioration problem becomes a challenge to port operators around the world including countries in Asia. In 2009, a three-year program from the Port Technology Group under the ASEAN-Japan Transport Partnership Program was started to overcome this problem by making a guideline to strategic maintenance for port structures. One of the participants of this group is in Indonesia, which assigns PT. Pelabuhan Indonesia I to IV as the operators of the national port.

Some of the facilities of Indonesian national port operators (NPOs), especially the berthing facilities, have been highly deteriorated especially for port branches outside of Java Island. The high level of deterioration across facilities owned by NPOs is mainly caused by the lack of regulated facilities maintenance system. Currently, monitoring of facilities is only being done by request or when a repair is going to be conducted to measure the damage and calculate the repair cost. While this monitor-on-demand method relatively works for the components on the top side of port structures, regular monitoring can detect lighter damage and may save repair or replacement cost compared to the repair of heavily damaged components. Moreover, components on the lower side of the berth structure tend to be overlooked if the current monitoring method is preserved since they are not easily visible. A completely corroded pile, for example, may lead to the failure of the berth structure as shown in Fig. 1. 


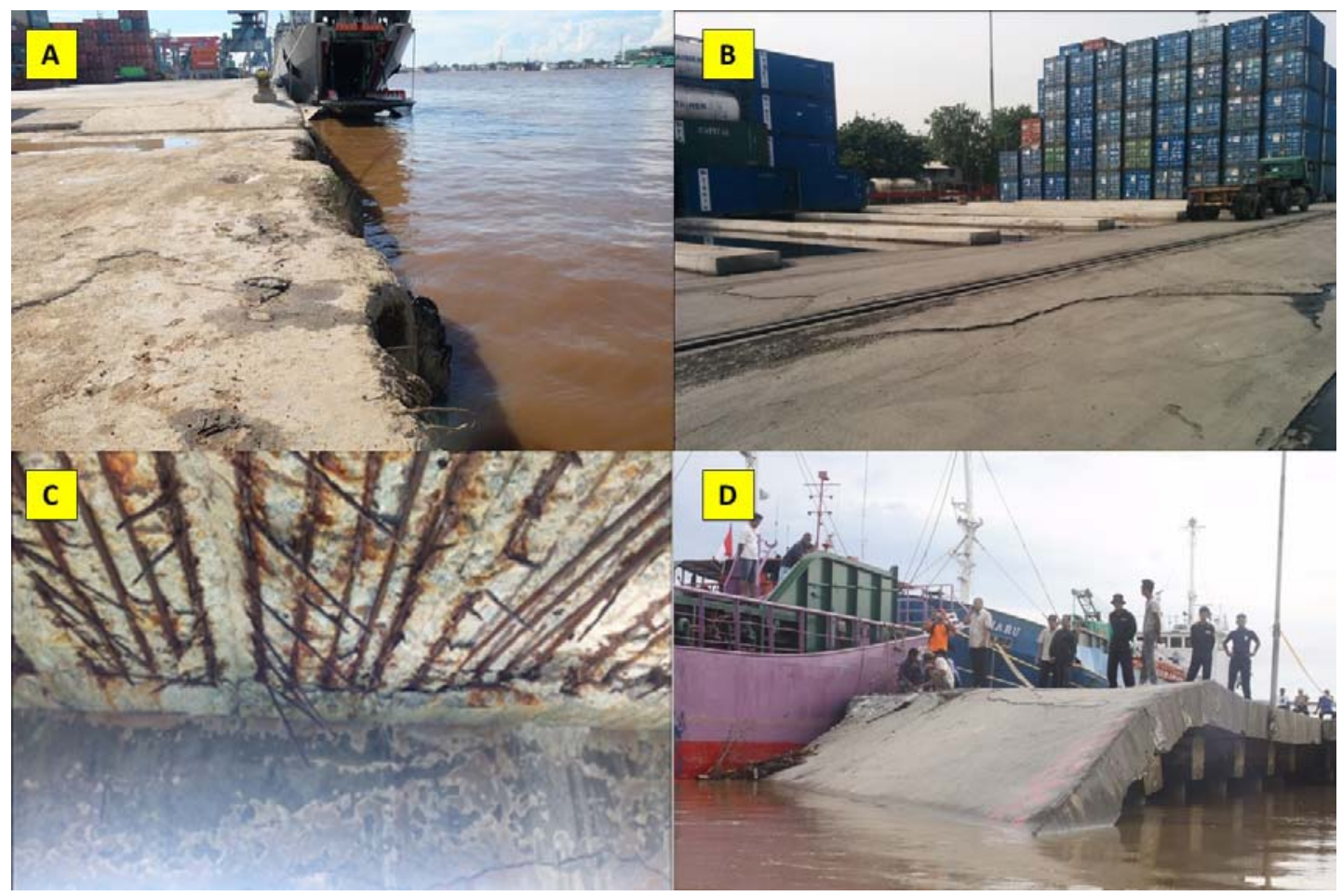

Fig. 1. Deteriorations of several facilities regulated by an NPO, consisting (A) damage to the bollard, fender, and faceline in a port in Kalimantan Island, (B) large crack on a container yard, (C) deterioration on the lower side concrete cover of slabs, and (D) a collapsed due to the pile failure. Photos by PT. Pelabuhan Indonesia II.

Maintenance is also often overlooked since the NPO branches prioritized their aim to achieve the highest profit possible in every year. While it is common to assume that the loss is higher if a structure fails compared to having the structure monitored and maintained periodically, it is currently impossible to quantify the loss accurately. There are currently no periodic monitoring data available to predict how often a maintenance should be carried out for every component in one facility.

The overarching aim of this study is to propose a simple maintenance management system for port facilities owned by NPOs in Indonesia in which the facility is limited only to berth structures. In this study, a berth structure facility from a NPOs will be used as an example. The method to make the system is discussed in Section 2. The discussion of the proposed maintenance management system is shown in Section 3. A hypothetical example case of this method is presented in Section 4 with the discussion about the result from the example case is given in Section 5. Finally, the study result is concluded in Section 6.

\section{Methods}

\section{A. Previous Studies on Port Facilities Monitoring Management}

Several studies have proposed the maintenance and monitoring system for ports. Zhang et al. [4], in addition to proposing a deterioration rate calculation method, also stated the deterioration grading which divides the deterioration into four grades depending on the size of cracking and intensity of corrosion. Specific inspection period for facilities is not specified in the study, but a five-yearly period is taken as one of the assumptions to make the Markov chain deterioration model. The example slab and beam inspection data from Port of Tokyo, however, has one to three-yearly period of inspection from 1999 to 2007.

Han-Padron Associates [4] divided the waterfront facilities inspection activity into four types, which are Routine Inspection, Rapid Assessment Inspection, Engineering Investigation, Repair Design Inspection. Between these inspection activity types, only the former has a periodic basis in which it should be done no more than once every 3-years. The scope of Routine Inspection, however, covers all elements within the waterfront facilities including both above and underwater inspection. In this Routine Inspection, all elements will have visual and/or tactile inspection while $10 \%$ of the elements will be inspected in high detail. The deterioration rate, or called "damage grade" in this literature, is divided into Not Inspected, No Damage, Minor, Moderate, Advanced, and Severe. 
Gaythwaite [5] divides the deterioration rate from the inspection result, which is "condition rating", of port facilities components into four as well, which consists of Minor, Moderate, Major, and Severe. After all components have been inspected and evaluated, a whole-structure rating will be given. The rating consists of Good, Satisfactory, Fair, Poor, Serious, and Critical, with Good rating means there are only minor problems at most that existed in the structure while Critical rating means there are component failures on at least one of its section and may spread wider throughout the entire structure. The maximum inspection period interval for underwater routine inspection, however, is relative to the result of last inspection and the aggressiveness of the environment. Next inspection should be carried out sooner if high deterioration rate is high and vice versa, with maximum inspection interval ranging from six years to 0.5 years.

\section{B. Previous Studies on Port Facilities Monitoring Management}

There are several things in common from the studies in the Section II A. Firstly, the proposed methods only cover the structural components of berth structures. Ship berthing and mooring components such as fenders and bollards as well as other supporting components such as stoppers, lamps, and drainages are not covered. NPOs, however, consider the coverage of these components in monitoring as important, most likely due to the limited human resource in the branch to monitor all facilities in the branch with its components.

Secondly, in practice, all condition ratings of components introduced by the studies are divided into six categories, which are Not Inspected, No Damage, Minor Damage, Average Damage, High Damage, and Critical Damage. For ports with limited resources, numerous facilities, and previously do not have any monitoring system, it can be difficult to cover all facilities of one branch within a set period and high level of detail. The priority of the newly introduced monitoring management system should be to cover the general condition of all facilities in every branch of NPOs first before continuing to the higher level of periodic inspection detail.

In its current state, maintenance of NPO branch facilities is the responsibility of the technical department of the branches. In some branches, due to the limited number of employee, technical department is often merged with the operational department. The recruitment of NPO employees on each branch is also regulated by the central office with no certain periodic recruitment. Usually, branches which bring large income will have more employee than branches with less income or even deficit.

Therefore, it is important to consider that the new facilities monitoring system should not depend the corporation to recruit new employees first before it can be initiated. It is also important to consider that the monitoring system, with currently available employees on the port branches, should be able to easily understand the monitoring system. If the condition of port facilities in branches can be covered properly by the introduced monitoring management, the feasibility to recruit additional employees to perform monitoring and more detailed inspection in branches should be higher. Ultimately, the monitoring management system can be improved to have a better understanding of the port facilities condition in branches.

\section{III.Proposed Maintenance Management System}

\section{A. Overview and Condition Assessment Activity}

Based on the previous studies and the current condition of NPOs regarding maintenance system, a new maintenance management system is introduced in this study. In general, the proposed maintenance management system is divided into three parts, which are Condition Assessment, Assessment Evaluation, and Follow Up as shown in Fig. 2. This study will be focused on the Condition Assessment and parametrization of overall facility condition. Assessment Evaluation and Follow Up parts, however, will not be discussed thoroughly. 


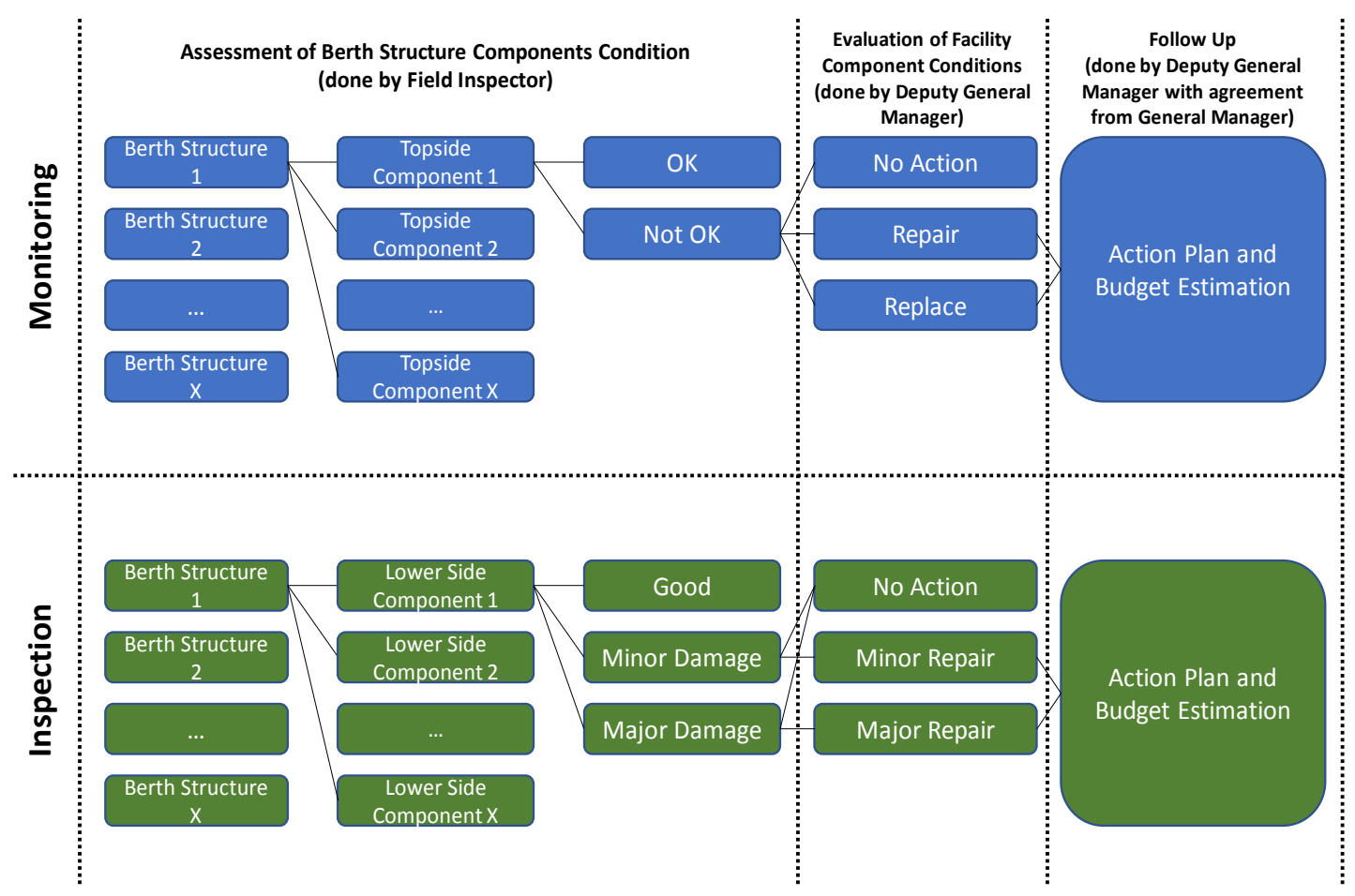

Fig. 2. Flowchart of the proposed maintenance management system (left to right)

Based on the frequency and the amount of detail, the Condition Assessment system for the berth structures is divided into two types which are 'Monitoring' and 'Inspection'. 'Monitoring' is an activity to visually check the condition of components on the top side of the berth structure. In 'Monitoring' activity, the condition of the component is only graded as 'OK' or 'Not OK' based on a certain parameter. The duration of 'Monitoring' for one berth structure depends on the size of the facility. However, in general, a 'Monitoring' should be able to be done in less than total effective working hours of one day. The outcome of 'Monitoring' activity on one berth structure consists of photos and details of damage of components that are assessed as 'Not OK'. Components that are assessed as "OK" are not documented nor commented.

'Inspection' activity is conducted for components located below the berth structure slabs which consists of piles, beams, and lower side of slabs. 'Inspection' is done in yearly basis since this activity requires more preparation to be conducted and assess more detailed information of the component condition. Due to its large scope, 'Inspection' activity for one facility may be conducted in over a day. The product from an 'Inspection' activity on a berth structure consists of photos and details of all inspected components regardless of its condition. The condition of components assessed in 'Inspection' is graded into 'Good', 'Minor Damage', and 'Major Damage'.

One cycle Monitoring/Inspection activity for a berth facility on a branch started with the field inspection by one or more Field Inspector (FI). The Field Inspector checks the condition of the berth facility with detail depending on the conducted activity and may ask the FI to redo the Monitoring/Inspection if required. After the Monitoring/Inspection of that day, the Monitoring/Inspection photo clarity and commenting on the components are then verified by the Branch Administrator (BA). The verified Monitoring/Inspection result is then passed to the Deputy General Manager (DGM) of the branch technical department. With the verified data, DGM checks the condition of components assessed by the FI. DGM may revise components with the assessed condition that does not match the photograph and/or the description.

After checking the verified data, the DGM(s), with approval from the General Manager (GM), set the action plan for components with 'Not OK' in 'Monitoring' activity or 'Minor Damage' and 'Major Damage' in 'Inspection' activity. The Monitoring/Inspection will be finalized by the if all components have been checked in the Monitoring/Inspection activity, meaning there will be no more adjustment to the assessment result as well as the set action plan. With the assessed overall facility condition, the Branch can plan the maintenance actions and budgeting for those components. A complete cycle of one Monitoring/Inspection activity is shown in Fig. 3. 


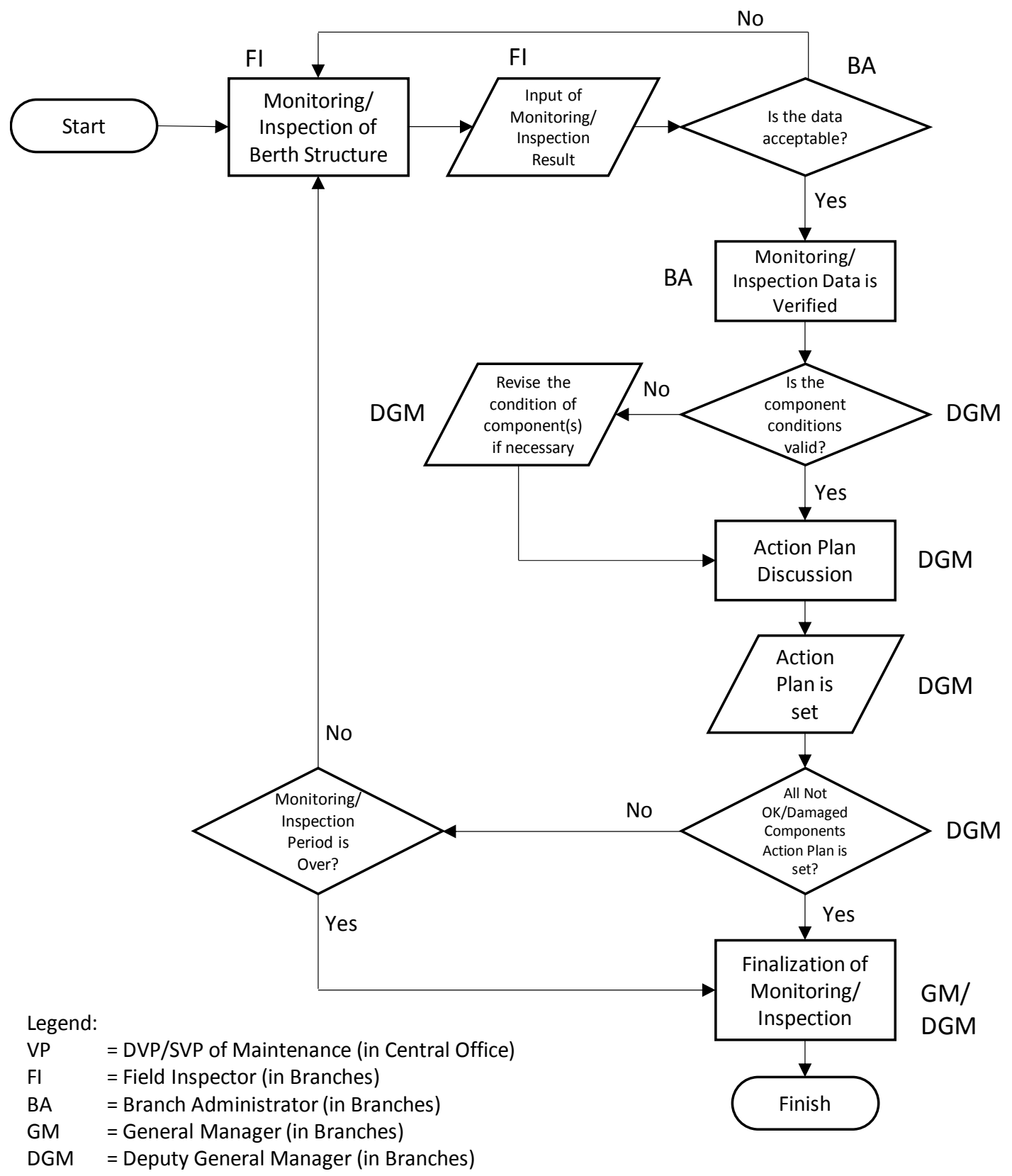

Fig. 3. Flowchart of one cycle of Monitoring/Inspection activity

\section{B. Facility Health}

The maintenance performance parameterization of each facility is represented as a Facility Health. Facility Health is composed by percentage accumulation of components with the same Component Type and Condition Type that has been accumulated and weighted based on its Component Category. To be easily understood by branch managers, Facility Health is represented in a pie chart as shown in Fig. 4. 

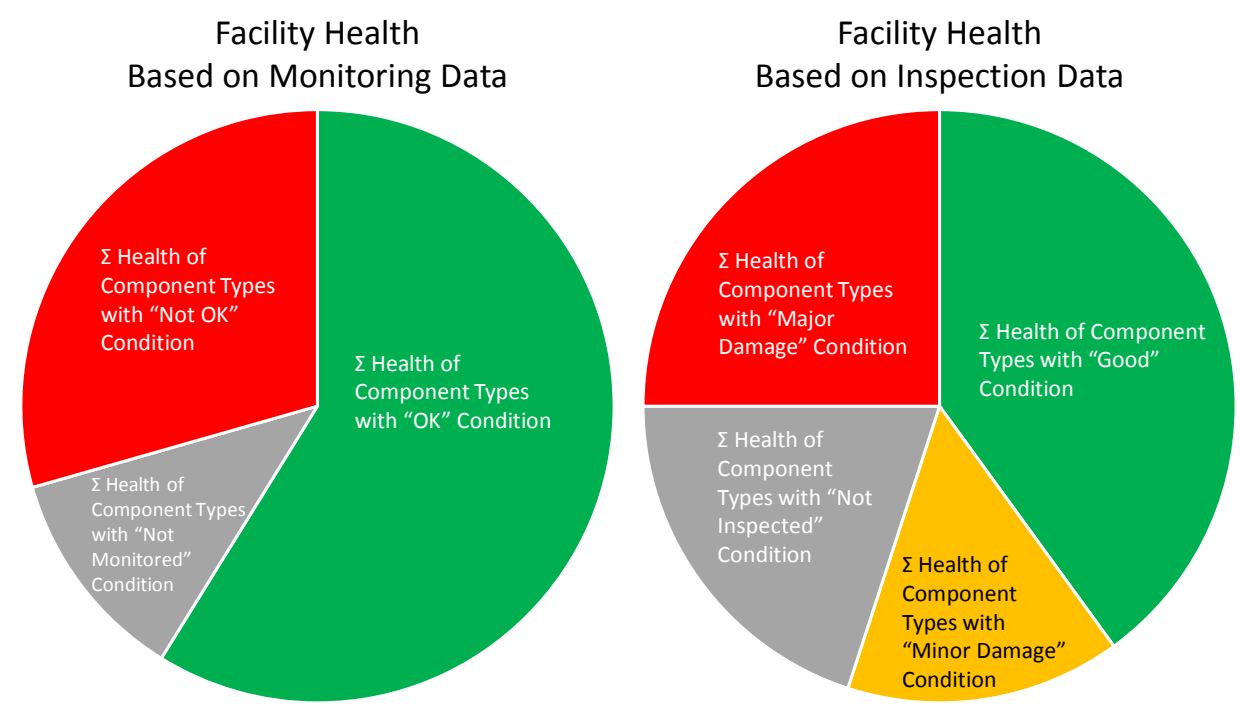

Fig. 4. Facility Health pie chart based on the 'Monitoring' and 'Inspection' Data

The calculation of Facility Health for one of the component condition type, which are OK, Not OK, or Not Monitored for 'Monitoring' activity and Good, Minor Damage, Major Damage, and Not Inspected for 'Inspection' activity, is the sum of all Component Type conditions which is as follows:

$$
F H=C C T_{1}+C C T_{2}+C C T_{3}+\cdots+C C T_{N}
$$

Where $F H$ is the facility health, $C C T_{n}$ is the condition for Component Type $n$ of the berth structure, and $N$ is the number of Component Type. The CCT for one Component Type is calculated as follows:

$$
C C T=\frac{\sum C C}{N_{\text {Component }}} \times W_{\text {Component Type }}
$$

Where $\Sigma C C$ is the sum of all Component condition of the Component Type and $W$ is weight score of the Component Type based on its category. The condition of all componentsis counted per individual unit with an exception for slabs, where one slab is counted as an area within piles of a berth structure connected to each other by single beams as shown in the example given in Section IV.

The Component Type category is divided into Main, Supporting, and Complementary, which is based on its importance to the berth structure operability and the cost to repair or replace the component it is damaged. In this study, Component Types are weighted at 70\%, 25\%, and 5\% for Main, Supporting, and Complementary category respectively. An example of Component Type Category along with its included Component Types and possible damages to each Component Type is shown in Table I. It should be noted that this Component Type categorization can be adjusted to better reflect the Facility Health according to the management. 
TABLE I. Example of Component Type Categorization and Possible Damages to the Component Types

\begin{tabular}{|c|c|c|c|c|}
\hline No. & $\begin{array}{l}\text { Component } \\
\text { Type Category }\end{array}$ & Weight & $\begin{array}{l}\text { Component } \\
\text { Types } \\
\text { Included } \\
\end{array}$ & Possible Damages \\
\hline \multirow[t]{4}{*}{1.} & \multirow[t]{4}{*}{ Main } & \multirow[t]{4}{*}{$70 \%$} & Upper Slab & $\begin{array}{l}\text { Cracking, spalling, exposed reinforcement, appearance } \\
\text { of corrosion on the slab surface, etc. }\end{array}$ \\
\hline & & & Lower Slab & $\begin{array}{l}\text { Cracking, spalling, exposed reinforcement, appearance } \\
\text { of corrosion on the slab surface, etc. }\end{array}$ \\
\hline & & & Beams & $\begin{array}{l}\text { Cracking, spalling, exposed reinforcement, appearance } \\
\text { of corrosion on the slab surface, etc. }\end{array}$ \\
\hline & & & Pile Caps & $\begin{array}{l}\text { Cracking, spalling, exposed reinforcement, appearance } \\
\text { of corrosion on the slab surface, etc. }\end{array}$ \\
\hline \multirow[t]{3}{*}{2.} & \multirow[t]{3}{*}{ Supporting } & \multirow[t]{3}{*}{$25 \%$} & Fender & Missing/loose bolts, torn rubber, fender lost, etc. \\
\hline & & & Bollard & $\begin{array}{l}\text { Missing/loose bolts, breaking, high corrosion, bollard } \\
\text { lost, etc. }\end{array}$ \\
\hline & & & Crane rail & Missing/loose bolts, corrosion, bent, etc. \\
\hline \multirow[t]{11}{*}{3.} & \multirow[t]{11}{*}{ Complementary } & \multirow[t]{11}{*}{$5 \%$} & Mark & Chipping, fading, etc. \\
\hline & & & Berth meter & $\begin{array}{l}\text { Faded/spalling number mark, berth meter disappeared, } \\
\text { etc. }\end{array}$ \\
\hline & & & Signage & $\begin{array}{l}\text { Missing/loose bolts, fading on the signs, bent/broken } \\
\text { signage pole, bent/broken signage board, etc. }\end{array}$ \\
\hline & & & Utility channel & Objects blocking the channel \\
\hline & & & Manhole & $\begin{array}{l}\text { Broken manhole hatch handle, chipped manhole hatch, } \\
\text { objects blocking the manhole. }\end{array}$ \\
\hline & & & Drainage & Objects blocking the drainage \\
\hline & & & $\begin{array}{c}\text { Electrical } \\
\text { utility }\end{array}$ & Electrical panel box corroded/door broken. \\
\hline & & & Lighting & $\begin{array}{l}\text { Light bulb worn out, light bulb broken/lost, light pole } \\
\text { bent/broken. }\end{array}$ \\
\hline & & & Stopper & Missing/loose bolts, corrosion, stopper lost, etc. \\
\hline & & & Cable tray & Objects blocking the cable tray. \\
\hline & & & etc. & \\
\hline
\end{tabular}

\section{IV.Proposed Maintenance Management System}

\section{A. Facility Health}

The example presented here only applies 'Monitoring' activity. However, 'Inspection' can also be done in the similar way to 'Monitoring' but with the scope of 'Inspection'. A hypothetical example results of 'Monitoring' activity shown in this study is conducted at DermagaBatu Bara 3 (Coal Wharf 3) in Banten Port. As the name implies, the structure is a wharf-type berth structure which is used for incoming ships to unload of coal cargo. The Coal Wharf 3 is a deck on pile structure with a size of $53 \mathrm{~m} \times 38 \mathrm{~m}$. Component Types that exist to be monitored including upper slab, berth meters, bollards, and fenders. Component Types which are beam, lower slab, pile cap, and pile also exist to be inspected. The layout of the Coal Wharf 3 is shown in Fig. 5.

\section{B. Monitoring Result}

In this 'Monitoring' example, it is found that slabs on the northwest and southeast ends of the wharf are chipped with the reinforcement bars exposed, two bollards have their bolts loose, and one berth meter has faded. These damaged components are marked as Not OK in the 'Monitoring' activity and impacts the Facility Health rating with the calculation detail shown inTable II. 


\section{Example Monitoring Result of Coal Wharf 3}

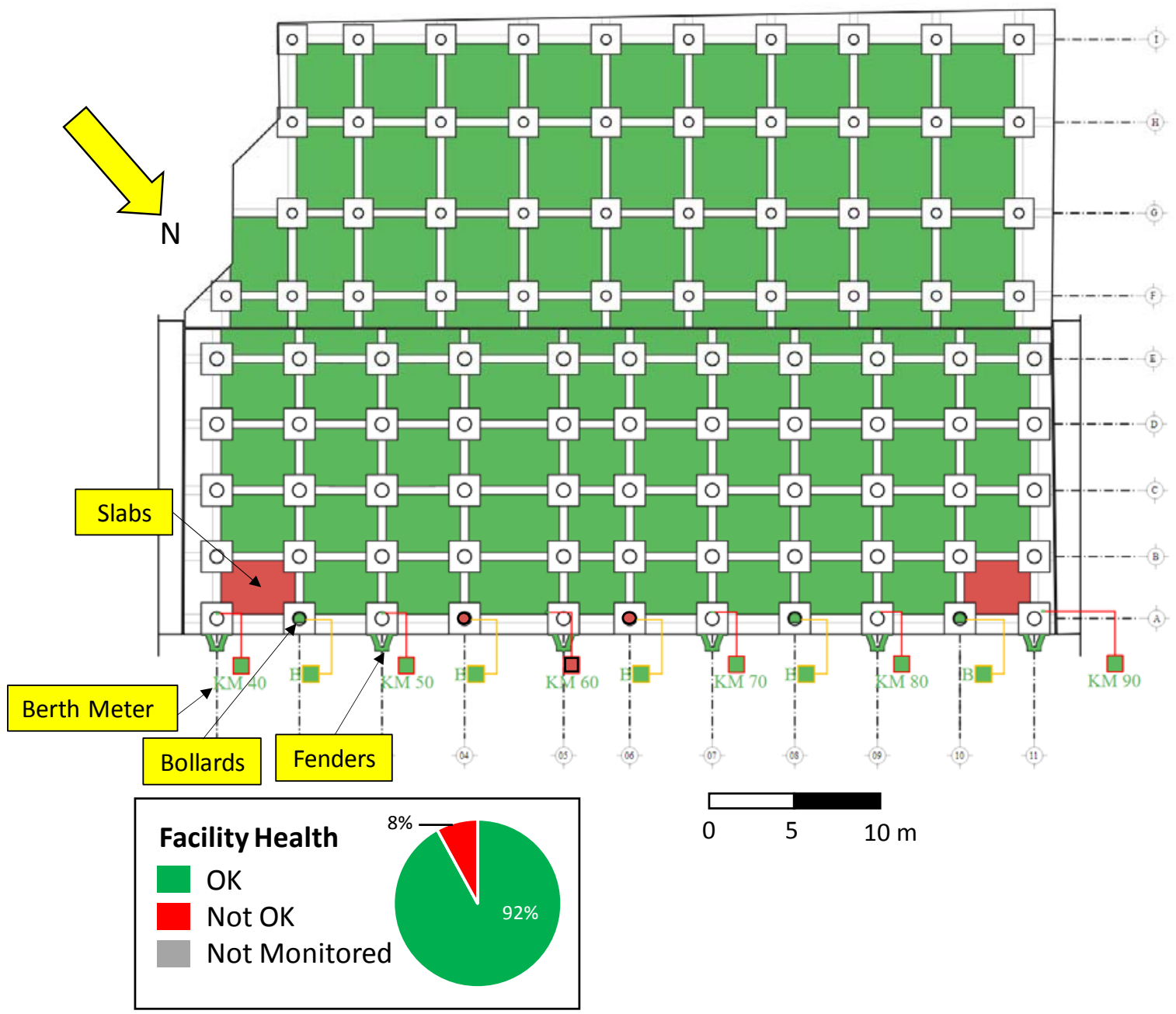

Fig. 5. The hypothetical result of 'Monitoring' activity on with the proposed maintenance management system. Damage is found on two slabs, two bollards, and one berth meter. These damages impacted the Facility Health rating.

TABLE II. Facility Health Calculation Table from Hypothetical 'Monitoring' Data of Coal Wharf 3

\begin{tabular}{|c|l|l|l|l|c|c|c|c|c|c|}
\hline \multirow{2}{*}{ No. } & \multirow{2}{*}{$\begin{array}{c}\text { Component } \\
\text { Type }\end{array}$} & \multicolumn{4}{|c|}{ Component Type Weight } & \multicolumn{2}{c|}{$\begin{array}{c}\text { Number of } \\
\text { Components Based on } \\
\text { the Assessment }\end{array}$} & \multicolumn{2}{|c|}{$\begin{array}{c}\text { Facility Health } \\
\text { Rounded Down for the } \\
\text { OK Condition) }\end{array}$} \\
\cline { 3 - 11 } & Main & Supporting & Complementary & OK & $\begin{array}{c}\text { Not } \\
\text { OK }\end{array}$ & $\begin{array}{c}\text { Not } \\
\text { Monitored }\end{array}$ & OK & $\begin{array}{c}\text { Not } \\
\text { OK }\end{array}$ & $\begin{array}{c}\text { Not } \\
\text { Monitored }\end{array}$ \\
\hline 1 & Slab & $70.00 \%$ & & & 76 & 2 & 0 & $68 \%$ & $2 \%$ & $0 \%$ \\
\hline 2 & Bollard & & $12.50 \%$ & & 3 & 2 & 0 & $8 \%$ & $5 \%$ & $0 \%$ \\
\hline 3 & Fender & & $12.50 \%$ & & 6 & 0 & 0 & $13 \%$ & $0 \%$ & $0 \%$ \\
\hline 4 & Berth Meter & & & $5.00 \%$ & 5 & 1 & 0 & $4 \%$ & $1 \%$ & $0 \%$ \\
\hline & Total & $70.00 \%$ & $25.00 \%$ & $5.00 \%$ & 90 & 5 & 0 & $92 \%$ & $8 \%$ & $0 \%$ \\
\hline
\end{tabular}

\section{Discussion}

Based on the hypothetical example 'Monitoring' result on the Coal Wharf 3, it is found that the Facility Health of Coal Wharf 3 is relatively good with $92 \%$ of the Components, after weighted depending on its category, is in OK condition. However, readjustment of Component Type categorization can also be carried out after this Facility Health calculation if necessary. For example, the recategorization of fender and bollard Component Type, which both are vital to the mooring operation. In this case, bollards can be moved to Complementary category since the price of new fenders may reach more than ten times of bollards. This move will also reduce the impact of damaged berth meter to the Facility Health since berth meters are relatively more affordable and easier to be repaired. 
On the other hand, a recategorization may also not to be carried out. If bollard is a component that got regularly damaged, 'Monitoring' activity will likely to pick up damaged bollards every month and reduce the Facility Health higher than if it is on the Complementary category. In management perspective, this high 'Not OK' part caused by damaged bollards can stimulate the sense of urgency of the branch to repair the component as soon as possible.

\section{VI.CONCLUSION}

A maintenance management system has been made and an example case of 'Monitoring' introduced in the system has been applied to a facility. The facility condition assessment based on the 'Monitoring' activity shows an acceptable result of reflecting the overall facility condition. If needed, the Component Type categorization can also be readjusted by the port branch management to alter how damage to the components affect the Facility Health.

As previously mentioned, the proposed method is intended to be simple, so it can be applied to branches of NPOs easily. Several methods can be used to improve the outcome of this system. Detail of the Facility Health calculation, for example, can be improved by expanding the Component Type into more categories to better reflect the importance and maintenance cost of the components. If there is enough resource in the branches, detailed measurement of damage can also be compulsory for both 'Monitoring' and 'Inspection'. As the technology improves, the time required to assess the condition of facilities, especially 'Inspection', might be reduced by incorporating unmanned vehicles such as quadcopters to quickly sweep the facility so the 'Inspection' can be carried out more often.

This system can also be adapted for other facilities on the port such as cargo yards, warehouses, roads, and offices. If these facilities are also covered in the maintenance management system, a parameterization similar to the Facility Health can also be applied in branch-scope in which the parameter is the accumulation of Facility Health of every facility covered in the system.

\section{ACKNOWLEDGMENT}

We would like to thank PT Pelabuhan Indonesia II as one of the NPOs in Indonesia for providing photos and a layout of one of their port facilities.

\section{REFERENCES}

[1] International Navigation Association, Life Cycle Management of Port Structures: General Principles, Report of Working Group No. 31 Supplement to Bulletin no. 99, Brussels: PIANC, 1998.

[2] Port Technology Group, Guidelines on Strategic Maintenance for Port Structures, ASEAN-JAPAN Transport Partnership, 2009.

[3] Zhang et al., Optimal Sustainable Life Cycle Maintenance Strategies for Port Infrastructures, Journal of Cleaner Production, 142 (2017), pp. 1693-1709, 2010.

[4] Han-Padron Associates, Waterfront Facilities Maintenance Management System: Inspection Guidelines Manual, New York City Economic Development Corporation, 1999.

[5] Gaythwaite, John W., Design of Marine Facilities for the Berthing, Mooring, and Repair of Vessels, 2nd ed, Reston, VA: ASE Press, 2004.

\section{AUTHOR PROFILE}

Julfikhsan Ahmad Mukhti is an MSc Engineering in the Coastal Environment graduate from the University of Southampton. He is also an undergraduate program assistant in Ocean Engineering Program, Faculty of Civil and Environment Engineering, InstitutTeknologi Bandung, Bandung, Indonesia.

Andojo Wurjanto is an Associate Professor at the Ocean Engineering Program, Faculty of Civil and Environment Engineering, InstitutTeknologi Bandung, Bandung, Indonesia. His research interest including Meteorological and Oceanographic (Metocean) Parameters, Wave-Coastal Structures Interaction, Simulation of Coastal Physical Process. Professionally, he was also involved on the design of coastal dike structure in the Indonesia Capital City of Jakarta as the design consultant.

Rizky Pitajeng is an engineer in PT. DinamaritamaKonsultan Rekayasa, which is a port and coastal engineering consulting company based in Bandung, West Java, Indonesia. In this study, she is responsible for checking the compatibility of formulas used to calculate the Facility Health.

Kartika Ayu Savitry is an engineer in PT. DinamaritamaKonsultan Rekayasa and helped coastal engineering researches of Ocean Engineering in InstitutTeknologi Bandung, Bandung, Indonesia. 